NOTICE: this is the author's version of a work that was accepted for publication in Neurocomputing. Changes resulting from the publishing process, such as peer review, editing, corrections, structural formatting, and other quality control mechanisms may not be reflected in this document. Changes may have been made to this work since it was submitted for publication. A definitive version was subsequently published in Neurocomputing, Vol. 142 (2014). DOI:

10.1016/j.neucom.2013.12.056 


\title{
A fuzzy ordinary regression method for modeling customer preference in
}

\section{tea maker design}

\author{
K.Y. Chan ${ }^{1}$, C. K. Kwong ${ }^{2}$ and M.C. Law ${ }^{3}$ \\ ${ }^{1}$ Department of Electrical and Computer Engineering, \\ Curtin University, \\ Australia \\ ${ }^{2}$ Department of Industrial and Systems Engineering, \\ The Hong Kong Polytechnic University, Hung Hom, Kowloon, \\ Hong Kong, PRC \\ ${ }^{3}$ G.E.W. Corporation Limited, Hong Kong, PRC
}

${ }^{1} \mathrm{~K}$. Y. Chan is the corresponding author of the paper. His email address is kit.chan@curtin.edu.au; The telephone number is (618) 92662945 and the fax number is 61892662819.

${ }^{2}$ C.K. Kwong's email address is c.k.kwong@polyu.edu.hk. The telephone number is (852) 27666610 and the fax number is (852) 23625267.

${ }^{3}$ M.C. Law’s email address is daniel@gewcorp.com. The telephone number is (852) 2343 8211 and the fax number is (852) 23431647. 


\begin{abstract}
-
Faced with fierce competition in marketplaces, manufacturers need to determine the appropriate settings of engineering characteristics of the new products so that the best customer preferences of the products can be obtained. To achieve this, functional models relating customer preferences to engineering characteristics need to be developed. As information regarding functional relationships between customer preferences are generally subjective or heuristic in nature, development of the customer preference models involve two uncertainties, namely fuzziness and randomness. Existing approaches use only fuzzy-based technologies to address the uncertainty caused by fuzziness. They are not designed to address the randomness of the observed data which is caused by a limited knowledge of the variability of influences between customer preferences and engineering characteristics. In this article, a fuzzy ordinary regression method is proposed to develop the customer preference models which are capable of addressing the two uncertainties of crispness and fuzziness of the customer preferences. A case study of a tea maker design which involves both uncertainties is used to demonstrate the effectiveness of the proposed method.
\end{abstract}

Keywords: New product development, fuzzy regression, tea makers, customer preference, fuzzy modelling 


\section{Introduction}

Nowadays, global competition and the development of novel manufacturing technologies have dramatically changed the operating environment of commercial industries (Moskowitz et al. 1997). Vigorous challenges have transformed many manufacturers from productioncentralized to customer-driven ones. If manufacturers were able to develop new products which satisfy customer preferences, this would give them a competitive advantage. New product planning is a complex process involving different perspectives including identifying customers and markets to be targeted, defining products to be developed and determining settings of engineering characteristics of the products (Xu et al. 2007). This paper aims at presenting a methodology to address the third issue which is to determine the optimal engineering characteristics of the products. It is the key to satisfying the customer preferences before manufacturing the products; this increases the probability of success for the new product in the marketplace (Chan et al. 2012).

To determine the optimal engineering characteristics of new products, quality function deployment (QFD) (Hauser and Clausing, 1988) has commonly been used. The QFD utilizes a matrix, namely houses of quality (HOQ), to relate customer preferences to engineering characteristics. Target values of engineering characteristics, normally housed at the bottom of a HOQ, provide definitive and quantitative technical specifications for new products. However, determining the HOQ associated with engineering characteristics is a complex decision-making process with multiple variables, and also it is normally accomplished in a subjective or heuristic manner; therefore, there is no guarantee that optimal engineering characteristics can be achieved.

Alternatively, we can develop a customer preference model which illustrates the relationship between customer preferences and engineering characteristics. Based on the customer preference model, optimal engineering characteristics of new products can be 
determined with respect to the specified customer preferences. This customer preference model is developed using numerical experimental data or customer survey data which investigates various customer preferences with respect to engineering characteristics (Chan et al. 2013). As the customer preferences are subjective and heuristic measures, fuzzy based modelling methodologies are commonly used. A fuzzy neural network model has been developed based on customers' survey data with different age groups, in order to study the customer preferences of the affective design of chair products (Park et al. 2004, Kwong et al. 2009). A similar approach based on a fuzzy neural network model has been developed in order to generate an image of a new product described with the corresponding engineering characteristics when particular customer preferences are given. A fuzzy inference system has been developed to represent the customer preference models for the affective design of mobile phones, where better modelling results can be obtained compared with the more complicated neural networks approach (Lin et al. 2007). Also, a fuzzy logic model has been proposed by integrating the customer preferences when using e-commerce into a single fuzzy quantity, in order to evaluate the overall customer satisfaction (Liu et al. 2007). However, these methods can generate only implicit customer satisfaction models, which give no explicit information. These methods are not widely utilized by engineers as no analytical information such as their significance for engineering characteristics can be indicated by the implicit customer satisfaction models. They reveal no explicit reasons for the design. Also, neural networks have the similar limitation that they cannot generate explicit information for new product development. Apart from these fuzzy modelling methods, statistical multivariate analysis techniques and genetic programming have been used to explain the relationship between the engineering characteristics of new products and customer preferences (Chan et al. 2011, Grigoroudis and Siskos 2002, Grigoroudis et al. 2008, Han et al. 2000, You et al. 
2006). However, these techniques have limitations due to their inability to capture the fuzziness of consumer requirements.

To address both the fuzziness and the explicitness of the customer preference models, a linear fuzzy regression has been applied, whereby the fuzzy coefficients are used to represent the uncertainty of customer preferences (Kim et al. 2000). The significance and fuzziness of each engineering characteristic is indicated by the fuzzy regression formulations. However, the fuzzy coefficients generated by the approach are in symmetric triangular form which is likely to create unnecessary outliers. Hence, it is not effective as a means of satisfying all features for customer preferences. Another approach of fuzzy regression integrated with asymmetric triangular fuzzy coefficients is applied to develop a functional model in QFD in order to represent the relationship between customer preferences and engineering characteristics (Chen et al. 2004, Chen et al. 2005, Fung et al. 2006). This approach is intended to increase the flexibility of the fuzzy regression in satisfying all customer preference data by the asymmetric triangular fuzzy coefficients. However, they are not designed to address the randomness of the observed data which is a result of the limited knowledge of variability of the amount of influence between customer preferences and engineering characteristics.

In this article, a fuzzy ordinary regression method, namely FORM, is proposed to model both crispness and fuzziness of the experimental data (Chang et al. 2001, Kwong et al. 2008), in order to address both the fuzziness and randomness of the customer preference models. The FORM is applied to the designing of a tea maker, as the experimental data used for investigating tea maker design contains the uncertainties associated with both randomness and fuzziness. Fuzzy regression is used to deal with uncertainty due to fuzziness and ordinary regression deals with uncertainty as random residuals. The FORM overcomes the limitation of fuzzy regression that only address uncertainty due to fuzziness and it overcomes the 
limitation of ordinary statistical regression that only address uncertainty due to randomness. The effectiveness of the FORM is evaluated through the design. Section II presents the customer preferences and the engineering characteristics when designing the tea makers. Section III demonstrates how the FORM can be formulated to develop the customer preference models for the tea makers. Section IV presents the experimental data used when investigating the customer preferences of the tea makers, and it also demonstrates the effectiveness of the FORM when designing the tea makers compared with other commonlyused fuzzy regression methods. A conclusion is given in Section V.

\section{Customer preference models for tea maker design}

In tea maker design, manufacturers generally aim to optimize two customer preferences when making tea, namely catechin content and tea concentration. Catechin content is a type of antioxidant found in great abundance in the leaves of the tea plant. Its health benefits have been under close examination, due to tea consumption being associated with health and longevity in many ancient cultures. Tea concentration elicits three affective streams from tea drinkers namely the rating of tea in terms of aroma, texture and overall taste tea. These two customer preferences indicate the preferences of the tea drinkers. Here the catechin content and the tea concentration are denoted as $y_{1}$ and $y_{2}$ respectively.

For brewing tea, the manufacturing company supporting this research implemented the following five steps as the mechanisms for the tea maker, an illustration of which is provided in Figure 1 in the Appendix. Based on the company supporting this research, five engineering characteristics namely $x_{1}, x_{2}, x_{3}, x_{4}$ and $x_{5}$ which are correlated to $y_{1}$ and $y_{2}$ are identified and discussed in the following. 


\section{Step 1: Heating the fresh water}

Two and half litres of fresh water are poured into container II of the tea maker, and are heated to 98 degrees Celsius.

\section{Step 2: Placing the tea and reheating the water}

Seventy grams of tea leaves are poured into the tea infuser which is then placed into container I of the tea maker. As the original temperature of the water decreases due to the heat lost by immersing the cold tea infuser, the water needs to be reheated in order to keep the temperature at a certain level. The reheat temperature is identified as the first engineering characteristic $x_{1}$.

\section{Step 3: First brewing cycle}

After the water is reheated, the tea is brewed through the first brewing cycle. The tea infuser is dropped into the water a certain number of times in order to release chemical contents. For each drop, the tea infuser is immersed in the water for 10 seconds and then 10 seconds elapse before the next drop. The number of drops is identified as the second engineering characteristic $x_{2}$.

\section{Step 4: Tea dipping}

The tea brewed through cycle one is immersed in the water in order to release the chemical contents. The amount of immersion time is identified as the third engineering characteristic $x_{3}$.

\section{Step 5: Second brewing cycle}

The second brewing cycle is intended to release more chemical contents into the water. Similar to the first brewing cycle, the tea infuser is immersed into the water with for a certain drops. At each drop, the tea infuser is immersed in the water for a certain amount of time and then 10 seconds elapse before the next drop. The number of drops the tea infuser is immersed into the water and the immersion time are 
identified as the fourth engineering characteristic $x_{4}$ and the fifth engineering characteristic $x_{5}$ respectively.

Therefore, the five engineering characteristics which are significant to the customer preferences of the tea makers are identified as: reheating temperature $\left(x_{1}\right)$, number of drops in the first brewing cycle $\left(x_{2}\right)$, dipping time $\left(x_{3}\right)$, number of drops in the second brewing cycle $\left(x_{4}\right)$, and immersion time in the second brewing cycle $\left(x_{5}\right)$.

A key feature of tea maker design is to develop the functional relationships, namely customer preference models, in order to correlate the specified customer preferences with the identified engineering characteristics. The customer preference models are given by equation (1).

$$
y_{i}=f_{i}(\mathbf{x}), i=1,2
$$

where $\mathbf{x}=\left(x_{1}, x_{2}, \cdots x_{5}\right)^{\mathrm{T}}$, and $f_{i}$, with $i=1$ and 2 , is the functional relationship between $y_{i}$ and the engineering characteristics. Based on the two $f_{i}$, maximization of customer preferences can be performed.

However, the acquisition of quantitative measures for the customer preferences is uncertain due to the randomness and fuzziness of the measures (Mauris et al. 2000). The randomness is due to a limited knowledge of the environment context and variability of a number of influences such as the tea itself and the unknown tolerance of temperature measure. The fuzziness is caused by the affective senses such as human measure reading and human taste of the tea. These uncertainties lead to shifts in or fluctuations of the true measures. Therefore, a fuzzy-ordinary regression method, namely FORM, which integrates both fuzzy regression and ordinary regression is proposed in order to develop the customer preference models that take into account these two types of uncertainties (Chang et al. 2001). 
Fuzzy regression is used to deal with uncertainty due to fuzziness and ordinary regression deals with uncertainty as random residuals.

\section{Fuzzy-ordinary regression method}

The following fuzzy-ordinary regression method (FORM) is proposed to generate the customer preference model in the form of fuzzy linear polynomial which is given in equation (2) as:

$$
\hat{y}_{i}=f_{i}(\boldsymbol{x})=\tilde{A}_{0, i}+\sum_{j=1}^{5} \tilde{A}_{j, i} x_{j}
$$

where $i=1,2 ; \hat{y}_{1}$ and $\hat{y}_{2}$ are the estimates of the customer preference models for the catechin content and tea concentration respectively. They are given by $\hat{y}_{1}=\left(\hat{y}_{1}^{C}, \hat{y}_{1}^{R}, \hat{y}_{1}^{L}\right)$ and $\hat{y}_{2}=\left(\hat{y}_{2}^{C}, \hat{y}_{2}^{R}, \hat{y}_{2}^{L}\right) ; \tilde{A}_{0, i}, \tilde{A}_{1, i}, .$. and $\tilde{A}_{5, i}$ are the fuzzy coefficients for $f_{i}(\boldsymbol{x})$; and $\tilde{A}_{j, i}$ is the triangular membership functions defined by $\tilde{A}_{j, i}=\left(a_{j, i}^{C}, a_{j, i}^{R}, a_{j, i}^{L}\right) ; a_{j, i}^{C}, a_{j, i}^{R}$ and $a_{j, i}^{L}$ are the fuzzy center, right spread and left spread of the fuzzy coefficient.

Based on equation (2), the $k$-th estimate with respect to the $k$-th experimental data is given by equation (3):

$$
\begin{aligned}
\hat{y}_{i}(k) & =\left(\hat{y}_{i}^{C}(k), \hat{y}_{i}^{L}(k), \hat{y}_{i}^{R}(k)\right)=\tilde{A}_{0, i}+\sum_{j=1}^{5} \tilde{A}_{j, i} x_{j, i}(k) \\
& =\left(a_{0, i}^{C}, a_{0, i}^{L}, a_{0, i}^{R}\right)+\left(\sum_{j=1}^{5} a_{j, i}^{C} x_{j, i}(k), \sum_{j=1}^{5} a_{j, i}^{\mathrm{L}} x_{j, i}(k), \sum_{j=1}^{5} a_{j, i}^{\mathrm{R}} x_{j, i}(k)\right)
\end{aligned}
$$

where $k=1, \ldots, m$; $m$ is the sample size; and $\left[x_{1, i}(k), x_{2, i}(k), x_{3, i}(k), x_{4, i}(k), x_{5, i}(k)\right]$ is the $k$-th set of experimental data. 
To perform the least square method, the residual error between the $k$-th estimate $\hat{y}_{i}(k)=\left[\hat{y}_{i}^{C}(k), \hat{y}_{i}^{R}(k), \hat{y}_{i}^{L}(k)\right]$ and the $k$-th observation $\tilde{y}_{i}(k)=\left[\tilde{y}_{i}^{C}(k), \tilde{y}_{i}^{L}(k), \tilde{y}_{i}^{R}(k)\right]$ is formulated as equation (4) based on weighted fuzzy arithmetic (G.J. Klir and B. Yuan 1995):

$$
\begin{aligned}
& \left(\hat{y}_{i}(k)-\tilde{y}_{i}(k)\right)^{2}=\left(\tilde{A}_{0, i}+\sum_{j=1}^{5} \tilde{A}_{j, i} x_{j, i}(k)-\tilde{y}_{i}(k)\right)^{2} \\
= & \left(a_{0, i}^{C}+\sum_{j=1}^{5} a_{j, i}^{C} x_{j, i}(k)-\tilde{y}_{i}^{C}(k)\right)^{2}+\frac{1}{12}\left[\left(a_{0, i}^{R}+\sum_{j=1}^{5} a_{j, i}^{R} x_{j, i}(k)-\tilde{y}_{i}^{R}(k)\right)^{2}+\left(a_{0, i}^{L}+\sum_{j=1}^{5} a_{j, i}^{L} x_{j, i}(k)-\tilde{y}_{i}^{L}(k)\right)^{2}\right] \\
+ & \frac{1}{3}\left(a_{0, i}^{C}+\sum_{j=1}^{5} a_{j, i}^{C} x_{j, i}(k)-\tilde{y}_{i}^{C}(k)\right)\left[\left(a_{0, i}^{R}+\sum_{j=1}^{5} a_{j, i}^{R} x_{j, i}(k)-\tilde{y}_{i}^{R}(k)\right)-\left(a_{0, i}^{L}+\sum_{j=1}^{5} a_{j, i}^{L} x_{j, i}(k)-\tilde{y}_{i}^{L}(k)\right)\right]
\end{aligned}
$$

where $\tilde{y}_{i}(k)$ is used for training. The total sum of the residual errors between the estimate $\hat{y}_{i}(k)$ and the observation $\tilde{y}_{i}(k)$, with $i=1, \ldots, m$, is obtained as shown as equation (5).

$$
\begin{aligned}
& E=\sum_{i=1}^{m}\left(\hat{y}_{i}(k)-\tilde{y}_{i}(k)\right)^{2}=\sum_{i=1}^{m}\left(\tilde{A}_{0, i}+\sum_{j=1}^{5} \tilde{A}_{j, i} x_{j, i}(k)-\tilde{y}_{i}(k)\right)^{2} \\
& =\sum_{i=1}^{m}\left(a_{0, i}^{C}+\sum_{j=1}^{5} a_{j, i}^{C} x_{j, i}(k)-\tilde{y}_{i}^{C}(k)\right)^{2}+\frac{1}{12} \sum_{i=1}^{m}\left[\left(a_{0, i}^{R}+\sum_{j=1}^{5} a_{j, i}^{R} x_{j, i}(k)-\tilde{y}_{i}^{R}(k)\right)^{2}+\left(a_{0, i}^{L}+\sum_{j=1}^{5} a_{j, i}^{L} x_{j, i}(k)-\tilde{y}_{i}^{L}(k)\right)^{2}\right] \\
& +\frac{1}{3} \sum_{i=1}^{m}\left(a_{0, i}^{C}+\sum_{j=1}^{5} a_{j, i}^{C} x_{j, i}(k)-\tilde{y}_{i}^{C}(k)\right)\left[\left(a_{0, i}^{R}+\sum_{j=1}^{5} a_{j, i}^{R} x_{j, i}(k)-\tilde{y}_{i}^{R}(k)\right)-\left(a_{0, i}^{L}+\sum_{j=1}^{5} a_{j, i}^{L} x_{j, i}(k)-\tilde{y}_{i}^{L}(k)\right)\right]
\end{aligned}
$$

In equation (5), the fuzzy coefficients, $\left(a_{j, i}^{C}, a_{j, i}^{L}, a_{j, i}^{R}\right)$ with $j=0, \ldots, 5$, are determined by minimizing the total sum of the residual errors, $E$. It can be performed by deriving equation (5) with respect to each element of $\left(a_{j, i}^{C}, a_{j, i}^{L}, a_{j, i}^{R}\right)$ with $j=0, \ldots, 5$, and then solve the derivatives, each of which is set to zero. 
The derivatives of equation (5) with respect to $a_{j, i}^{C}$ are given by equation (6).

$$
\begin{aligned}
\frac{\partial E}{\partial a_{0, i}^{C}}= & m a_{0, i}^{C}+\left(\sum_{k=1}^{m} x_{1, i}(k)\right) a_{1, i}^{C}+\left(\sum_{k=1}^{m} x_{2, i}(k)\right) a_{2, i}^{C}+\cdots+\left(\sum_{k=1}^{m} x_{5, i}(k)\right) a_{5, i}^{C} \\
& \quad-\sum_{k=1}^{m} \tilde{y}_{i}^{C}(k)=0, \text { with } j=0 ; \\
\frac{\partial E}{\partial a_{1, i}^{C}=} & \left(\sum_{k=1}^{m} x_{1, i}(k)\right) a_{0, i}^{C}+\left(\sum_{k=1}^{m} x_{1, i}(k)^{2}\right) a_{1, i}^{C}+\left(\sum_{k=1}^{m} x_{1, i}(k) \cdot x_{2, i}(k)\right) a_{2, i}^{C}+\cdots \\
& +\left(\sum_{k=1}^{m} x_{1, i}(k) \cdot x_{5, i}(k)\right) a_{5, i}^{C}-\sum_{k=1}^{m}\left(x_{1, i}(k) \cdot \tilde{y}_{i}^{C}(k)\right)=0, \text { with } j=1 ; \\
: \quad & : \\
\frac{\partial E}{\partial a_{5, i}^{C}=} & \left(\sum_{k=1}^{m} x_{5, i}(k)\right) a_{0, i}^{C}+\left(\sum_{k=1}^{m} x_{5, i}(k) \cdot x_{1, i}(k)\right) a_{1, i}^{C}+\left(\sum_{k=1}^{m} x_{5, i}(k) \cdot x_{2, i}(k)\right) a_{2, i}^{C}+\cdots \\
& +\left(\sum_{k=1}^{m} x_{5, i}(k)^{2}\right) a_{5, i}^{C}-\sum_{k=1}^{m}\left(x_{5, i}(k) \cdot \tilde{y}_{i}^{C}(k)\right)=0, \text { with } j=5 ;
\end{aligned}
$$

The derivatives of equation (5) with respect to $a_{j, i}^{L}$ and $a_{j, i}^{R}$, are given by equations (7) and (8) respectively.

$$
\begin{aligned}
& \frac{\partial E}{\partial a_{0, i}^{L}}= m a_{0, i}^{L}+\left(\sum_{k=1}^{m} x_{1, i}(k)\right) a_{1, i}^{L}+\left(\sum_{k=1}^{m} x_{2, i}(k)\right) a_{2, i}^{L}+\cdots+\left(\sum_{k=1}^{m} x_{5, i}(k)\right) a_{5, i}^{L} \\
& \quad-\sum_{k=1}^{m} \tilde{y}_{i}^{L}(k)=0 \text {, with } j=0 ; \\
& \frac{\partial E}{\partial a_{1, i}^{L}}=\left(\sum_{k=1}^{m} x_{1, i}(k)\right) a_{0, i}^{L}+\left(\sum_{k=1}^{m} x_{1, i}(k)^{2}\right) a_{1, i}^{L}+\left(\sum_{k=1}^{m} x_{1, i}(k) \cdot x_{2, i}(k)\right) a_{2, i}^{L}+\cdots \\
&+\left(\sum_{k=1}^{m} x_{1, i}(k) \cdot x_{5, i}(k)\right) a_{5, i}^{L}-\sum_{k=1}^{m}\left(x_{1, i}(k) \cdot \tilde{y}_{i}^{L}(k)\right)=0 \text {, with } j=1 ;
\end{aligned}
$$




$$
\begin{aligned}
\frac{\partial E}{\partial a_{5, i}^{L}}= & \left(\sum_{k=1}^{m} x_{5, i}(k)\right) a_{0, i}^{L}+\left(\sum_{k=1}^{m} x_{5, i}(k) \cdot x_{1, i}(k)\right) a_{1, i}^{L}+\left(\sum_{k=1}^{m} x_{5, i}(k) \cdot x_{2, i}(k)\right) a_{2, i}^{L}+\cdots \\
& +\left(\sum_{k=1}^{m} x_{5, i}(k)^{2}\right) a_{5, i}^{L}-\sum_{k=1}^{m}\left(x_{5, i}(k) \cdot \tilde{y}_{i}^{L}(k)\right)=0 \text {, with } j=5 ;
\end{aligned}
$$

and

$$
\begin{aligned}
& \frac{\partial E}{\partial a_{0, i}^{R}}= m a_{0, i}^{R}+\left(\sum_{k=1}^{m} x_{1, i}(k)\right) a_{1, i}^{R}+\left(\sum_{k=1}^{m} x_{2, i}(k)\right) a_{2, i}^{R}+\cdots+\left(\sum_{k=1}^{m} x_{5, i}(k)\right) a_{5, i}^{R} \\
& \quad-\sum_{k=1}^{m} \tilde{y}_{i}^{R}(k)=0, \text { with } j=0 ; \\
& \frac{\partial E}{\partial a_{1, i}^{R}=}\left(\sum_{k=1}^{m} x_{1, i}(k)\right) a_{0, i}^{R}+\left(\sum_{k=1}^{m} x_{1, i}(k)^{2}\right) a_{1, i}^{R}+\left(\sum_{k=1}^{m} x_{1, i}(k) \cdot x_{2, i}(k)\right) a_{2, i}^{R}+\cdots \\
&+\left(\sum_{k=1}^{m} x_{1, i}(k) \cdot x_{5, i}(k)\right) a_{5, i}^{R}-\sum_{k=1}^{m}\left(x_{1, i}(k) \cdot \tilde{y}_{i}^{R}(k)\right)=0, \text { with } j=1 ; \\
& \quad: \quad: \\
& \quad+\left(\sum_{k=1}^{m} x_{5, i}(k)^{2}\right) a_{5, i}^{R}-\sum_{k=1}^{m}\left(x_{5, i}(k) \cdot \tilde{y}_{i}^{R}(k)\right)=0, \text { with } j=5 ;
\end{aligned}
$$

Each of the above three sets of equations represented in equations (6), (7) and (8) is similar to the formulation of the linear least square regression. Therefore, based on the fuzzy centers of the collected data, $\tilde{y}_{i}^{C}(k)$ with $k=1,2, \ldots, m$, the fuzzy centers of fuzzy coefficients in (6), $a_{j, i}^{C}$ with $j=0,1, \ldots, 5$, can be obtained using the linear least square regression. Based on the collected fuzzy data corresponding fuzzy left spreads (i.e. $\tilde{y}_{i}^{L}(k)$ with $k=1,2, \ldots, m$ ) and right spreads (i.e. $\tilde{y}_{i}^{R}(k)$ with $\left.k=1,2, \ldots, m\right)$, the fuzzy left spread in equation (7), $a_{j, i}^{L}$ with $j=0,1, \ldots, 5$, and the fuzzy right spread in equation (8), $a_{j, i}^{R}$ with $j=0,1, \ldots, 5$, can be obtained respectively, using the linear least square regression. By solving the three sets of equations 
(6), (7) and (8), the fuzzy centers, the left spreads and the right spreads of triangular fuzzy coefficients respectively can be obtained.

\section{Evaluation and validation of the fuzzy-ordinary regression method for tea product design}

\subsection{Experimental set-up}

The proposed FORM was used to develop the customer satisfactory models of the tea maker. In the experiments, five engineering characteristics of the tea makers were studied; the ranges of the engineering characteristics are given in Table 1 . The engineering characteristics were quantized into four levels as illustrated in the table.

Table 1: Experimental ranges and settings of the five engineering characteristics for the tea maker design

\begin{tabular}{|c|c|c|c|c|c|}
\hline $\begin{array}{c}\text { Engineering } \\
\text { characteristics }\end{array}$ & $\begin{array}{c}\text { Reheating } \\
\text { temperature } \\
\text { (degrees Celsius) }\end{array}$ & $\begin{array}{c}\text { Number of } \\
\text { drops in the } \\
\text { first brewing } \\
\text { cycle }\end{array}$ & $\begin{array}{c}\text { Dipping } \\
\text { time } \\
\text { (minutes) }\end{array}$ & $\begin{array}{c}\text { Number of } \\
\text { drops in the } \\
\text { second } \\
\text { brewing cycle }\end{array}$ & $\begin{array}{c}\text { Immersion time } \\
\text { in the second } \\
\text { brewing cycle } \\
\text { (seconds) }\end{array}$ \\
\cline { 2 - 6 } & $x_{1}$ & $x_{2}$ & $x_{3}$ & $x_{4}$ & $x_{5}$ \\
\hline $\begin{array}{c}\text { Experimental } \\
\text { ranges }\end{array}$ & $93-99$ & $1-4$ & $8.5-10$ & $2-5$ & $10-40$ \\
\hline Level 1 & 93 & 1 & 8.5 & 2 & 10 \\
\hline Level 2 & 95 & 2 & 9 & 3 & 20 \\
\hline Level 3 & 97 & 3 & 9.5 & 4 & 30 \\
\hline Level 4 & 99 & 4 & 10 & 5 & 40 \\
\hline
\end{tabular}

As there are five engineering characteristics and each of them is quantized by four levels, 1024 (or $4^{5}$ ) experiments need to be conducted when a full factorial design is used. If two minutes are required for each experiment, 2048 minutes (or 34.13 hours) are required for the full factorial design which is too time-consuming. Therefore, the orthogonal array namely $L_{16}\left(4^{5}\right)$ illustrated in Table 2 in the Appendix was used for the experimental design to study 
the effects of the five engineering characteristics with four levels. The 16 configurations of the experimental trials are shown in Table 2. As an example, the $1^{\text {st }}$ experiment is conducted based on the five engineering characteristics with level one settings. The $5^{\text {th }}$ experiment is conducted based on the settings of $x_{1}$ with level $1, x_{2}$ with level 2, $x_{3}$ with level 2, $x_{4}$ with level 3, and $x_{5}$ with level 4 . As only 16 experiments are required to study the main effects of the five engineering characteristics, 1008 (or 1024-16) experiments can be saved compared with the full factorial design. Also, the configurations of $L_{16}\left(4^{5}\right)$ have a pairwise balancing property, whereby every combination of engineering characteristics included in the experiments is the same. This minimizes the number of experiments required and enables a balanced study of the significance of each engineering characteristic.

In order to study the fuzziness and randomness of the two customer preferences regarding catechin content and tea concentration, the experiments configured with $L_{16}\left(4^{5}\right)$ were repeated twice; the experimental results were recorded and are shown in Table 3 in the Appendix.

\subsection{Development of customer preference models}

The effectiveness of the customer preference models regarding catechin content and tea concentration can be evaluated by investigating the mean absolute errors, which are defined by $e_{M A E}^{i}$, as formulated in equation (9).

$$
e_{\text {MAE }}^{i}=\frac{1}{m} \sum_{k=1}^{m}\left|\frac{y_{i}^{M}(k)-f_{i}\left(x_{1}(k), x_{2}(k), x_{3}(k), x_{4}(k), x_{5}(k)\right)}{y_{i}^{M}(k)}\right| \times 100 \%
$$

where $e_{\text {MAE }}^{1}$ and $e_{\text {MAE }}^{1}$ represent the errors for catechin content and tea concentration respectively; $y_{i}^{M}(k)$ is the average of the two trials regarding the $k$-th experiment for the customer preference model, $f_{i} ; x_{1}(k), x_{2}(k), x_{3}(k), x_{4}(k)$ and $x_{5}(k)$ are parameter 
values for the $k$-th experiment; $f_{i}\left(x_{1}(k), x_{2}(k), x_{3}(k), x_{4}(k), x_{5}(k)\right)$ is the estimate regarding the $k$-th experiment; and $m$ is the number of experiments performed. Here $m=16$, as 16 experiments have been conducted.

Using the 16 pieces of experimental data and their results shown in Table 3, the proposed FORM was implemented using Matlab for this tea maker design, where the FORM was used to determine the fuzzy coefficient with fuzzy center, $a_{j, i}^{C}$, right spread, $a_{j, i}^{R}$, and left spread, $a_{j, i}^{L}$, with $i=1,2$ and $j=1,2, \ldots 5$ as given in equations (6), (7) and (8) respectively. The customer preference model for catechin content is developed as equation (10):

$$
\begin{aligned}
& y_{1}=(1.609,0.899,0.892)+\left(0.171,2.859 \times 10^{-13}, 2.842 \times 10^{-13}\right) \cdot x_{1}+(0.055,0.026,0.026) \cdot x_{2} \\
& +(-0.042,0.245,0.245) \cdot x_{3}+(-0.105,1.567,1.582) \cdot x_{4}+(0.010,0.279,0.276) \cdot x_{5}
\end{aligned}
$$

where $e_{M A E}^{1}$ was found as $3.225 \%$. The customer preference model for tea concentration is developed as equation (11):

$$
\begin{aligned}
& y_{2}=(1.609,0.676,0.670)+(0.296,0.390,0.390) \cdot x_{1}+\left(0.043,-3.455 \times 10^{-10},-3.456 \times 10^{-10}\right) \cdot x_{2} \\
& +(0.075,0.538,0.5335) \cdot x_{3}+(0.075,0.328,0.329) \cdot x_{4}+(-0.031,0.951,0.950) \cdot x_{5}
\end{aligned}
$$

where $e_{M A E}^{2}$ was found as $2.135 \%$.

In order to compare the results obtained by the proposed FORM, two commonly applied fuzzy regressions, namely TS-fuzzy regression (TS-FR) (Tanaka et al. 1982) and Peters-fuzzy regression (Peters-FR) (Peters 1994), have been used to develop the customer preference models. The customer preference models developed by the three methods and the mean absolute errors obtained by the developed models are summarized in Table 4. For Catechin content, results shows that the mean absolute errors obtained by FORM, TS-FR, and 
Peters-FR are $3.225 \%, 4.380 \%$ and $3.359 \%$ respectively. For tea concentration, those obtained by FORM, TS-FR, and Peters-FR are 2.135\%, 2.206\% and 2.592\% respectively. The results indicate that the proposed FORM can obtain the smallest mean absolute errors compared with the other two tested fuzzy regression methods. Hence, the FORM is able to fit the experimental data compared with the other two. Also, for the Catechin content, the fuzzy coefficients of the linear polynomial developed by FORM indicate that $x_{1}$ has the smallest fuzziness and $x_{4}$ has the largest fuzziness. For the tea concentration, they indicate that $x_{2}$ has the smallest fuzziness and $x_{5}$ has the largest fuzziness. This result indicates that different fuzziness can be generated when developing models with different consumer preferences. Hence, the fuzzy polynomials with fuzzy coefficients are capable to provide more tolerance information for each engineering characteristics while the linear polynomial which only consists of constant coefficients.

Table 4: Customer preference models developed by FORM, TS-FR, and Peters-FR

\begin{tabular}{|c|c|c|c|}
\hline $\begin{array}{l}\text { Customer } \\
\text { preferences }\end{array}$ & $\begin{array}{l}\text { Modeling } \\
\text { methods }\end{array}$ & Developed models & $\begin{array}{l}\text { Mean } \\
\text { absolute } \\
\text { errors }\end{array}$ \\
\hline \multirow[t]{3}{*}{$\begin{array}{l}\text { Catechin } \\
\text { content }\end{array}$} & FORM & $\begin{array}{l}y_{1}=(1.609,0.899,0.892)+\left(0.171,2.859 \times 10^{-13}, 2.842 \times 10^{-13}\right) \cdot x_{1} \\
+(0.055,0.026,0.026) \cdot x_{2}+(-0.042,0.245,0.245) \cdot x_{3} \\
+(-0.105,1.567,1.582) \cdot x_{4}+(0.010,0.279,0.276) \cdot x_{5}\end{array}$ & $3.225 \%$ \\
\hline & TS-FR & $\begin{array}{l}y_{1}=(1.621,1.080)+\left(0.2410,2.274 \times 10^{-13}\right) \cdot x_{1}+\left(0.045,-8.526 \times 10^{-14}\right) \cdot x_{2} \\
+\left(-0.006,4.548 \times 10^{-13}\right) \cdot x_{3}+(-0.201,0) \cdot x_{4}+\left(0.009,3.979 \times 10^{-13}\right) \cdot x_{5}\end{array}$ & $4.38 \%$ \\
\hline & Peters-FR & $\begin{array}{l}y_{1}=(1.596,4.467)+(0.176,0.092) \cdot x_{1}+(0.059,0.092) \cdot x_{2} \\
+(-0.036,0.092) \cdot x_{3}+(-0.099,0.092) \cdot x_{4}+(0.015,0.092) \cdot x_{5}\end{array}$ & $3.359 \%$ \\
\hline \multirow[t]{3}{*}{$\begin{array}{l}\text { Tea } \\
\text { concentration }\end{array}$} & FORM & $\begin{array}{l}y_{2}=(1.609,0.676,0.670)+(0.296,0.390,0.390) \cdot x_{1} \\
+\left(0.043,-3.455 \times 10^{-10},-3.456 \times 10^{-10}\right) \cdot x_{2}+(0.075,0.538,0.5335) \cdot x_{3} \\
+(0.075,0.328,0.329) \cdot x_{4}+(-0.031,0.951,0.950) \cdot x_{5}\end{array}$ & $2.135 \%$ \\
\hline & TS-FR & $\begin{array}{l}y_{1}=(1.618,0.697)+(0.282,0.022) \cdot x_{1}+(0.035,0.000) \cdot x_{2} \\
+(0.088,0.000) \cdot x_{3}+(-0.0220,0.000) \cdot x_{4}+(0.042,0.000) \cdot x_{5}\end{array}$ & $2.206 \%$ \\
\hline & Peters-FR & $\begin{array}{l}y_{1}=(1.618,0.184)+(0.347,0.085) \cdot x_{1}+(0.022,0.007) \cdot x_{2} \\
+(0.053,0.007) \cdot x_{3}+(-0.052,0.007) \cdot x_{4}+(0.019,0.007) \cdot x_{5}\end{array}$ & $2.592 \%$ \\
\hline
\end{tabular}


To further validate the generalization capability of the customer preference models developed by the three methods, cross-validation was conducted using 12 validation tests. Four pieces of experimental data were randomly selected as the test data from the 16 pieces of experimental data, and are shown in Table 5. The remaining 12 pieces of data were used to develop the customer preference models. The table summarizes the generalization capabilities of the three methods, and shows the generalization errors and the ranks with respect to the mean absolute errors. It indicates that the generalization errors obtained by the FORM are generally smaller than those of the other two methods, TS-FR and Peters-FR. Also for Catechin content, the mean generalization errors obtained by FORM, TS-FR and PetersFR are given by $5.654 \%, 7.393 \%$ and $6.097 \%$ respectively. For tea concentration, those obtained by FORM, TS-FR and Peters-FR are given by $11.37 \%, 12.99 \%$ and $28.45 \%$ respectively. Hence, FORM is more capable to generate consumer preference models than the other tested methods.

Figure 2 shows the relative improvements when each of the two other tested methods is compared with the FORM method, where the relative improvement is the difference between the results obtained by FORM and the other tested method, divided by the result obtained by the other tested method.

They indicate the relative differences between the results obtained by the FORM and those obtained by the two tested methods. The figure shows that almost all relative improvements are greater than one. Hence, FORM is generally better than both TS-FR and Peters-FR. The better results can be explained by the fact that FORM addresses both the randomness and fuzziness when analysing the experimental data, but the commonly used fuzzy regression methods, TS-FR and Peters-FR address only the fuzziness when analysing the experimental data. 
Table 5: Generalization errors for the customer preference models developed by FORM, TSFR and Peters-FR

\begin{tabular}{|c|c|c|c|c|c|c|c|}
\hline \multirow{2}{*}{$\begin{array}{c}\text { Cross } \\
\text { validation } \\
\text { number }\end{array}$} & \multirow[t]{2}{*}{ Test data } & \multicolumn{3}{|c|}{ Catechin content } & \multicolumn{3}{|c|}{ Tea concentration } \\
\hline & & $\begin{array}{c}\text { FORM } \\
(\%)\end{array}$ & $\begin{array}{c}\text { TS-FR } \\
\text { (\%) }\end{array}$ & $\begin{array}{c}\text { Peters- } \\
\text { FR } \\
(\%) \\
\end{array}$ & $\begin{array}{c}\text { FORM } \\
(\%)\end{array}$ & $\begin{array}{c}\text { TS-FR } \\
\text { (\%) }\end{array}$ & $\begin{array}{c}\text { Peters- } \\
\text { FR } \\
(\%) \\
\end{array}$ \\
\hline 1 & $\begin{array}{cl}2 & 4 \\
10 & 13 \\
\end{array}$ & 13.77 & 7.655 & 4.803 & 11.00 & 19.89 & 169.0 \\
\hline 2 & $\begin{array}{rl}4 & 5 \\
11 & 12\end{array}$ & 5.085 & 8.411 & 5.749 & 11.87 & 14.76 & 15.11 \\
\hline 3 & $\begin{array}{cc}1 & 4 \\
9 & 14 \\
\end{array}$ & 2.773 & 9.536 & 9.370 & 8.800 & 9.744 & 10.00 \\
\hline 4 & $\begin{array}{rl}5 & 9 \\
13 & 15\end{array}$ & 7.051 & 7.695 & 7.348 & 15.03 & 16.15 & 16.20 \\
\hline 5 & $\begin{array}{cl}2 & 6 \\
15 & 16 \\
\end{array}$ & 5.978 & 6.600 & 5.989 & 8.594 & 9.645 & 10.79 \\
\hline 6 & $\begin{array}{cr}2 & 7 \\
9 & 15 \\
\end{array}$ & 7.202 & 7.500 & 7.415 & 11.01 & 11.35 & 12.5 \\
\hline 7 & $\begin{array}{cc}1 & 5 \\
8 & 10 \\
\end{array}$ & 1.722 & 6.028 & 5.604 & 14.03 & 16.78 & 24.1 \\
\hline 8 & $\begin{array}{cc}4 & 12 \\
13 & 16 \\
\end{array}$ & 3.649 & 8.606 & 4.655 & 10.85 & 10.75 & 12.00 \\
\hline 9 & $\begin{array}{rr}3 & 5 \\
9 & 11 \\
\end{array}$ & 6.784 & 7.219 & 6.416 & 12.06 & 12.54 & 13.77 \\
\hline 10 & $\begin{array}{cc}5 & 7 \\
8 & 14 \\
\end{array}$ & 5.217 & 5.142 & 5.072 & 13.91 & 15.28 & 14.69 \\
\hline 11 & $\begin{array}{cc}3 & 8 \\
9 & 10 \\
\end{array}$ & 5.885 & 5.906 & 5.840 & 12.47 & 12.95 & 14.19 \\
\hline 12 & $\begin{array}{cc}1 & 2 \\
4 & 14\end{array}$ & 2.736 & 8.422 & 4.898 & 6.794 & 6.036 & 29.09 \\
\hline $\mathbf{M e}$ & & 5.654 & 7.393 & 6.097 & 11.37 & 12.99 & 28.45 \\
\hline
\end{tabular}



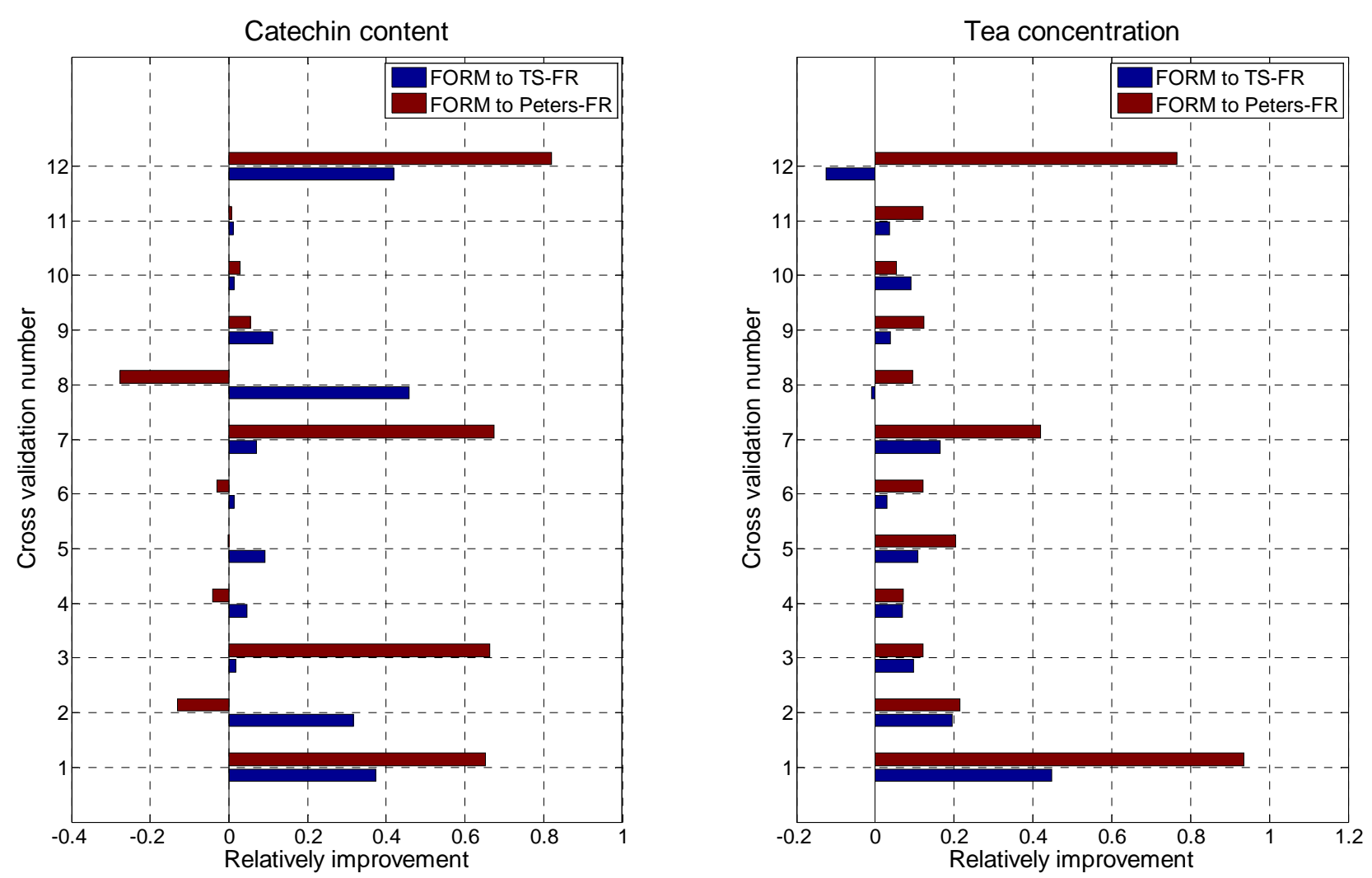

Figure 2: Relative improvements between FORM to TS-FR and Peters-FR

To optimize the customer preferences of the tea makers, $y_{1}$ and $y_{2}$, determination of the five optimal engineering characteristics are necessary. The optimization problem can be formulated by maximizing $y_{1}$ and $y_{2}$ as given in equation (12), as the proposed FORM can generate the best consumer preference models among all tested methods. As Problem (12) is a Pareto-based multi-objective problem, it can be solved by the multi-objective genetic algorithm richly represented in the literature for solving multi-objective problems (Knowles and Corne, 2000; Zitzler and Thiele, 1999). 
$\max \left\{\begin{aligned} y_{1}= & (1.609,0.899,0.892)+\left(0.171,2.859 \times 10^{-13}, 2.842 \times 10^{-13}\right) \cdot x_{1}+(0.055,0.026,0.026) \cdot x_{2} \\ & +(-0.042,0.245,0.245) \cdot x_{3}+(-0.105,1.567,1.582) \cdot x_{4}+(0.010,0.279,0.276) \cdot x_{5} \\ y_{2}= & (1.609,0.676,0.670)+(0.296,0.390,0.390) \cdot x_{1}+\left(0.043,-3.455 \times 10^{-10},-3.456 \times 10^{-10}\right) \cdot x_{2} \\ & +(0.075,0.538,0.5335) \cdot x_{3}+(0.075,0.328,0.329) \cdot x_{4}+(-0.031,0.951,0.950) \cdot x_{5}\end{aligned}\right.$ subject to: $x_{1} \in\{93 . .99\} ; x_{2} \in\{1 . .4\} ; x_{3} \in\{8.5 . .10\} ; x_{4} \in\{2 . .5\} ;$ and $x_{5} \in\{10 . .40\}$.

\section{Conclusion}

In this article, a modelling method namely FORM was proposed to develop customer preference models for new product development. It is intended to address uncertainties by considering both the randomness and fuzziness of customer preferences, as these are generally subjective or heuristic. It aims to overcome the existing shortcomings in developing customer-requirement-based methods for new product development. The current methods are able to address the fuzziness of customer preferences but they cannot address the randomness caused by a limited knowledge of the amount of influence exerted by customer preferences.

To evaluate the effectiveness of the proposed FORM, a case study of a tea maker design was carried out by developing the customer preference models. The intention was to study the two customer preferences regarding catechin content and tea concentration which are subject measures for indicating the preferences of the tea drinkers. The effectiveness of the customer preference models developed by FORM was compared with those developed by the two fuzzy regression methods, TS-fuzzy regression and Peters-fuzzy regression. Results of the comparison show that the models developed based on FORM produce fewer training errors and fewer validation errors. This can be explained by the fact that analysis of the experimental data shows that FORM addresses both the randomness and fuzziness. In the future, we will improve the generalization capability of the FORM by using irregular fuzzy membership function on representing the fuzzy number. Also development of fuzzy classification method (Bocaniala et al. 2004, Ranawana 2004) is the next stage of this 
research in order to determine whether the consumer preference of the design is satisfaction, as customer satisfaction is also fuzzy.

\section{References}

Bocaniala C.D., Costa J.S., Palade V. 2004. "A novel fuzzy classification solution for fault diagnosis", Journal of Intelligent and Fuzzy Systems 15 (3): 195-205.

Chan K.Y., Kwong C.K., Dillon T.S. 2012. “Computational Intelligence Techniques for New Product Design, Springer: Studies in Computational Intelligence 403”.

Chan K.Y., Kwong C.K., Wong T.C., 2011. "Modelling customer satisfaction for product development using genetic programming.” Journal of Engineering Design 22 (1): 55-68

Chen Y., Tang J., Fung R.Y.K., Ren Z. 2004. "Fuzzy regression-based mathematical programming model for quality function deployment.” International Journal of Production Research 42: 1009-10027.

Chen Y., Chen L. 2005. “A non-linear possibilistic regression approach to model functional relationships in product planning.” International Journal of Advanced Manufacturing Technology 28 (11-12): 1175-1181.

Fung R.Y.K., Chen Y., Tang J., Tu Y. "Estimating functional relationships for product planning under uncertainties.” Fuzzy Sets and Systems 157: 98-120.

Grigoroudis E., Siskos Y. 2002. "Preference disaggregation for measuring and analyzing customer satisfaction The MUSA method.” European Journal of Operational Research, 143: $148-170$. 
Grigoroudis E., Litos C., Moustakis V. A., Politis Y., Tsironis L. 2008. “The assessment of user-perceived web quality: Application of a satisfaction benchmarking approach.” European Journal of Operational Research 187 (2008): 1346-1357.

Han S.H., Yun M.H., Kim K.J., Kwahk J. 2000. "Evaluation of product usability: development and validation of usability dimensions and design elements based on empirical models.” International Journal of Industrial Ergonomics 26: 477-488.

Hauser J.R., Clausing D. 1998. “The house of quality.” Harvard Business Review 1998: 6373.

Hsiao S.W., Tsai H.C. 2005. “Applying a hybrid approach based on fuzzy neural network and genetic algorithm to product form design.” International Journal of Industrial Ergonomics 35: 411-428.

Klir G.J., Yuan B. 1995. “Fuzzy Sets and Fuzzy Logic - Theory and Applications.” PrenticeHall, Englewood Cliffs, NJ.

Knowles, J.D., Corne, D.W. 2000. “Approximating the non-dominated front using the pareto archived evolution strategy.” Evolutionary Computation 8: 149-172.

Kwong C.K., Wong T.C., Chan K.Y. 2009. “A methodology of generating customer satisfaction models for new product development using a neuro-fuzzy approach”, Expert Systems with Applications 36 (8): 11262-11270.

Kwong C.K., Chen Y., Chan K.Y., Wong H. 2008. "The hybrid fuzzy least-squares regression approach to modeling manufacturing processes”, IEEE Transactions on Fuzzy Systems 16 (3): 644-651 
Lin Y.C., Lai H.H., Yeh C. H. 2007. “Consumer-oriented product form design based on fuzzy logic: A case study of mobile phones.” International Journal of Industrial Ergonomics 37: 531-543.

Liu X., Zeng X., Xu Y., Koehl L. 2007. “A fuzzy model for customer satisfaction index in ecommerce.” Mathematics and Computers in Simulation 77: 512-521.

Mauris G., Berrah L., Foulloy L., Haurat A. 1990. "Fuzzy handling of measurement errors in instrumentation.” IEEE Transactions on Instrumentation and Measurement 49(1): 89-93.

Moskowitz H., Kim K. J. 1997. “QFD optimizer: a novice friendly quality function deployment decision support system for optimizing product designs.” Computers \& Industrial Engineering 32: 641-655.

Park J., Han S.H. 2004. “A fuzzy rule-based approach to modeling affective user satisfaction towards office chair design.” International Journal of Industrial Ergonomics 34: 31-47.

Peters G. 1994. "Fuzzy linear regression with fuzzy intervals.” Fuzzy Sets and Systems 63: 45-55.

Ranawana R., Palade V., Bandara G. 2004. “An efficient fuzzy method for handwritten character recognition.” Proceedings of the Interational Conference on Knowledge-Based Intelligent Information and Engineering Systems, 698-707.

Tanaka H., Uejima S., Asai K. 1982. “Linear regression analysis with fuzzy model.” IEEE Transactions on Systems, Man, and Cybernetics 12: 903-907.

Xu L., Li Z., Li S., Tang F. 2007. “A decision support system for product design in concurrent engineering.” Decision Support Systems 42: 2029-2042.

You H., Ryu T., Oh K., Yun M.H., Kim K.J. 2006. “Development of customer satisfaction models for automotive interior materials.” International Journal of Industrial Ergonomics 36: 323-330. 
Zitzler E. and Thiele L. 1999. "Multiobjective evolutionary algorithms: a comparative case study and the strength pareto approach.” IEEE Transactions on Evolutionary Computation 3(4): 257-271. 


\section{Appendix}

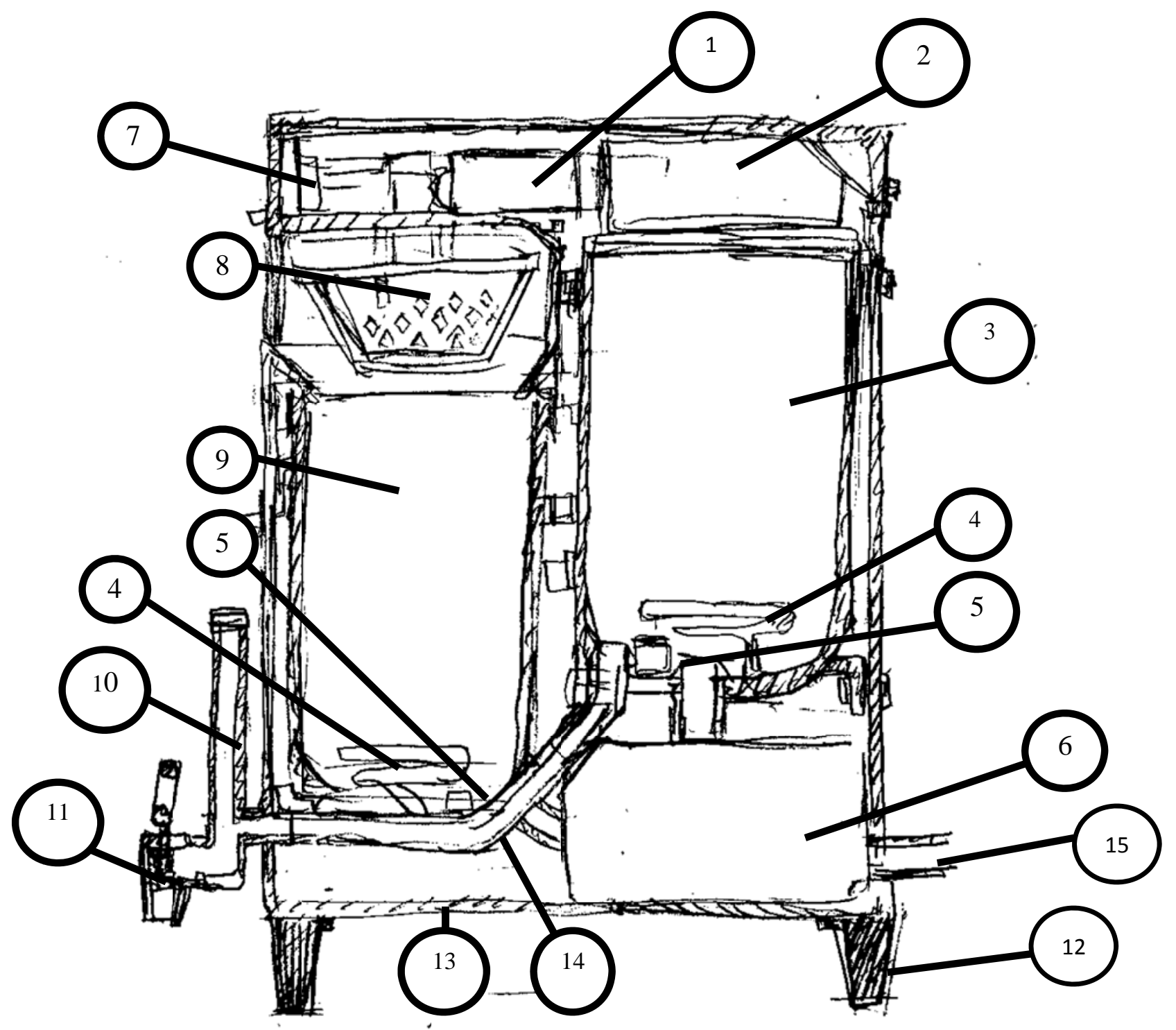

(a) tea maker

1. Vertical conveyer (motor)

3. Container II

5. Volume \& thermo sensor

7. Display unit / UI / Buzzer

9. Container I

11. Water outlet

13. Casing

15. Power cord \& water inlet
2. Control unit / Transformer

4. Heater

6. Pump unit

8. Tea infuser assembly

10. Volume indicator

12. Stand

14. Piping linkage 

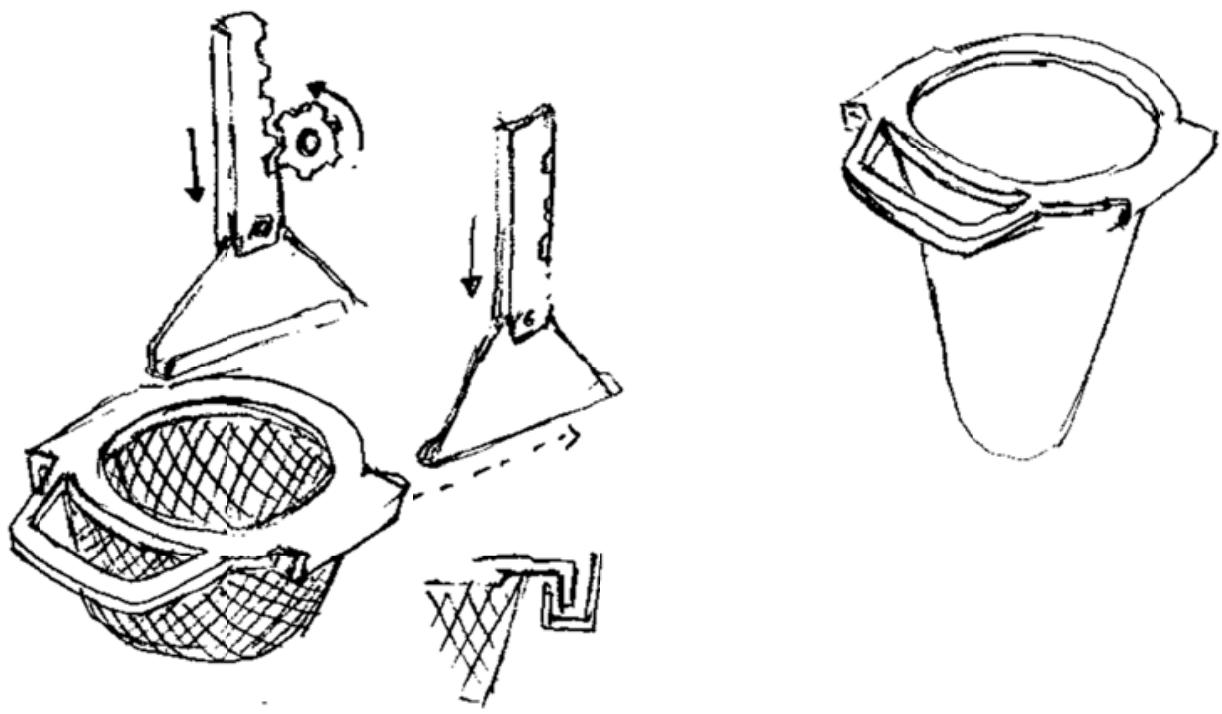

(b) tea infuser

Figure 1: Illustration of (a) the tea maker and (b) the tea infuser 
Table 2: The orthogonal array, $L_{16}\left(4^{5}\right)$, used for the tea maker design

\begin{tabular}{|c|c|c|c|c|c|}
\hline Experiments & $\begin{array}{c}\text { Reheating } \\
\text { temperature } \\
\text { (degrees } \\
\text { Celsius) }\end{array}$ & $\begin{array}{l}\text { Number } \\
\text { of drops } \\
\text { in the first } \\
\text { brewing } \\
\text { cycle }\end{array}$ & $\begin{array}{l}\text { Dipping } \\
\text { time } \\
\text { (minutes) }\end{array}$ & $\begin{array}{l}\text { Number of } \\
\text { drops in the } \\
\text { second } \\
\text { brewing } \\
\text { cycle }\end{array}$ & $\begin{array}{l}\text { Immersion time } \\
\text { in the second } \\
\text { brewing cycle } \\
\text { (seconds) }\end{array}$ \\
\hline 1 & 1 & 1 & 1 & 1 & 1 \\
\hline 2 & 1 & 2 & 2 & 2 & 2 \\
\hline 3 & 1 & 3 & 3 & 3 & 3 \\
\hline 4 & 1 & 4 & 4 & 4 & 4 \\
\hline 5 & 2 & 1 & 2 & 3 & 4 \\
\hline 6 & 2 & 2 & 1 & 4 & 3 \\
\hline 7 & 2 & 3 & 4 & 1 & 2 \\
\hline 8 & 2 & 4 & 3 & 2 & 1 \\
\hline 9 & 3 & 1 & 3 & 4 & 2 \\
\hline 10 & 3 & 2 & 4 & 3 & 1 \\
\hline 11 & 3 & 3 & 1 & 2 & 4 \\
\hline 12 & 3 & 4 & 2 & 1 & 3 \\
\hline 13 & 4 & 1 & 4 & 2 & 3 \\
\hline 14 & 4 & 2 & 3 & 1 & 4 \\
\hline 15 & 4 & 3 & 2 & 4 & 1 \\
\hline 16 & 4 & 4 & 1 & 3 & 2 \\
\hline
\end{tabular}


Table 3: Mean of Catechin reading and tea concentration results

\begin{tabular}{|c|c|c|c|c|c|c|}
\hline \multirow[t]{2}{*}{ Experiments } & \multicolumn{2}{|c|}{ First trial } & \multicolumn{2}{|c|}{ Second trial } & \multicolumn{2}{|c|}{$\begin{array}{c}\text { Average of the two } \\
\text { trials }\end{array}$} \\
\hline & $\begin{array}{l}\text { Catechin } \\
\text { content }\end{array}$ & $\begin{array}{c}\text { Tea } \\
\text { concentration }\end{array}$ & $\begin{array}{l}\text { Catechin } \\
\text { content }\end{array}$ & $\begin{array}{c}\text { Tea } \\
\text { concentration }\end{array}$ & $\begin{array}{l}\text { Catechin } \\
\text { content }\end{array}$ & $\begin{array}{c}\text { Tea } \\
\text { concentration }\end{array}$ \\
\hline 1 & 1.53 & 1.545 & 1.683 & 1.566 & 1.6065 & 1.5555 \\
\hline 2 & 1.607 & 1.676 & 1.735 & 1.77 & 1.671 & 1.723 \\
\hline 3 & 1.481 & 1.886 & 1.563 & 1.443 & 1.522 & 1.6645 \\
\hline 4 & 1.628 & 1.85 & 1.503 & 1.587 & 1.5655 & 1.7185 \\
\hline 5 & 1.362 & 1.792 & 1.57 & 1.77 & 1.466 & 1.781 \\
\hline 6 & 1.566 & 1.898 & 1.623 & 1.58 & 1.5945 & 1.739 \\
\hline 7 & 1.542 & 1.887 & 1.829 & 1.779 & 1.6855 & 1.833 \\
\hline 8 & 1.497 & 1.857 & 1.666 & 1.812 & 1.5815 & 1.8345 \\
\hline 9 & 1.766 & 1.934 & 1.608 & 1.767 & 1.687 & 1.8505 \\
\hline 10 & 1.602 & 2.047 & 1.686 & 1.647 & 1.644 & 1.847 \\
\hline 11 & 1.68 & 1.916 & 1.796 & 1.777 & 1.738 & 1.8465 \\
\hline 12 & 1.66 & 1.963 & 1.793 & 1.866 & 1.7265 & 1.9145 \\
\hline 13 & 1.709 & 2.062 & 1.664 & 2.099 & 1.6865 & 2.0805 \\
\hline 14 & 1.707 & 1.778 & 1.934 & 2.103 & 1.8205 & 1.9405 \\
\hline 15 & 1.443 & 1.812 & 1.717 & 1.907 & 1.58 & 1.8595 \\
\hline 16 & 1.844 & 2.009 & 1.922 & 2.005 & 1.883 & 2.007 \\
\hline
\end{tabular}

